\section{Locating iron production sites in Telangana, India using satellite imagery}

\author{
Smriti Haricharan ${ }^{1, *}$, Nagabhushana ${ }^{2}$, \\ Sharada Srinivasan ${ }^{3}$, M. B. Rajani ${ }^{3}$ and \\ S. Ranganathan ${ }^{3}$
}

\begin{abstract}
${ }^{1}$ Department of History, School of Humanities and Social Science, Block E, Lower Ground Floor, Shiv Nadar University,

NH91, Tehsil Dadri, Gautam Buddha Nagar 201 314, India

${ }^{2}$ National Institute of Advanced Studies,

Indian Institute of Science Campus, Bengaluru 560 012, India

${ }^{3}$ Bangalore University, Ramachandra Road, Ambdekar Veedhi,

Sampangi Rama Nagar, Bengaluru 560 009, India
\end{abstract}

The use of satellite imagery is explored in mapping the distribution of archaeometallurgical sites for iron and steel production and as a tool for potential reconnaissance in northern districts of Telangana. Travellers' accounts from at least the seventeenth century suggest that this was an area where pre-industrial iron and steel production flourished, which is also testified by the vast amount of archaeometallurgical debris in the region. The geographical distribution of ferrous metal production sites within this landscape has been documented by integrating data from surface surveys on over 100 archaeometallurgical sites with satellite imagery. Despite the constraints that the surface sites could not be dated by archaeological excavation, this pilot study explores how satellite imagery and related experimental procedures may be used to complement surface archaeometallurgical surveys and reconnaissance efforts.

Keywords: GPS survey, iron, satellite imagery, Telangana, wootz steel.

TELANGANA which formed part of the former princely state of Hyderabad ruled by the Nizams until the mid 20th century, also included the medieval province of Golconda. It was merged with the state of Andhra Pradesh of the Indian Union in 1956, bound by the states of Maharashtra, Chhattisgarh and Odisha to the north, and Karnataka to the west; it was granted separate statehood in 2014. The four northern districts of Telangana, i.e. Karimnagar, Nizamabad, Warangal and Adilabad, in particular have had a rich legacy of iron and steel production. Numerous travellers' accounts of the late medieval and colonial period such as of Voysey and Tavernier mention the repute of steel made by crucible processes in the Golconda region which was exported as far as Persia and which was later found to be higher carbon steel ${ }^{1-7}$.

The problem in the Indian context is that the chronology for the beginning and continued practice of iron production has not been clearly defined either by relative dating

*For correspondence. (e-mail: smriti.haricharan@snu.edu.in) methods or absolute dating. Based largely on relative dating it is suggested that the introduction of iron possibly began as early as $1000 \mathrm{BCE}$, continuing well into the medieval period ${ }^{8}$. In the past, there had not been much archaeometallurgical study on early iron objects ${ }^{9}$, although this has been changing in recent times with more studies, including ethnographic analysis of iron tools ${ }^{10,11}$. Problems of dating have been compounded by the fact that surviving archaeometallurgical iron production sites have not generally been properly surveyed or placed within their landscapes.

Although the important contribution of southern India in the development of crucible steel technology has been recognized, not much had been known or recorded of the primary iron production technology that underpinned this specialized industry ${ }^{12}$. It has been suggested that the beginnings of iron technology in southern India coincided with the 'megalithic period' of South India ${ }^{13}$. Iron objects were introduced in Andhra Pradesh between 750 and 500 BCE (ref. 14). While wrought iron has scarcely any carbon impurities, it can be carburized to make steel which has improved hardness. An early example of an object which had been hardened through quenching is dated to 810 BCE from Bihar ${ }^{15}$. Although systematic studies on the historical trajectory of crucible steel production have not been made, new insights are emerging from archaeological and archaeometallurgical studies for the early prevalence of higher carbon steels in the southern Indian subcontinent going back to the megalithic and early historic period ${ }^{7}$. For example, from the megalithic site of Kadebakele, c. $700 \mathrm{BCE}$, tiny rings were identified which seem to have been made of pearlitic steel ${ }^{16}$, while from megalithic Kodumanal in Tamil Nadu (c. 3rd century BCE) and Pattinam (1st century), remnants of highcarbon steel akin to wootz were identified ${ }^{17}$.

Although the trajectory and antiquity of the sites surveyed in the Telangana region cannot be ascertained as yet, numerous accounts point to the flourishing late medieval trade in wootzor crucible steel in the Golconda region. By the late 17 th century, the Dutch began separately developing their industry in the Godaveri belt ${ }^{15}$. This makes the study of archaeometallurgical landscapes from this region interesting, as it gives an ideal scenario to explore differences between the two production landscapes; of iron production on the one hand and the local crucible steel production on the other. Two different types of ore that were utilized in the Godavari belt have also been previously discussed ${ }^{15}$. Some sites such as the ferrous metal production site of Konasamudram, where crucible steel remains are also found and which was surveyed in this study, may have used magnetic banded iron ore, since these formations are found close to the site ${ }^{15}$.

This communication is based on the extensive fieldwork undertaken over the past decade by Jaikishan ${ }^{2}$ in identifying ferrous metal production sites in northern Telangana (2009), followed by the present authors 
through the NIAS-Exeter UKIERI 'Pioneering Metallurgy' project. This project was carried out in collaboration with Gill Juleff and Jaikishan, which undertook further archaeometallurgical documentation of over a 100 sites, including GPS recordings ${ }^{2,3}$. The iron production sites from Telangana may date anywhere from the early historical period to the medieval period and cannot be dated with better resolution at present as there have been few comprehensive studies involving stratigraphic excavation and scientific studies. The archaeometallurgical remains and slag heaps that have been documented in Telangana region are related to either iron production or wootz steel production activities. One way in which we can differentiate the two types of production sites is by examining them within their contiguous landscape, and thereby giving a spatial context to these archaeological sites.

The range of archaeometallurgical debris studied here includes slag heaps with remnants of tap slag, crucible remnants, furnace wall remains, tuyeres and occasionally pot sherds. Since these are surface finds without much associated datable pottery, it has been difficult to attribute dates. As such, in the Indian context not much is known in terms of metal production sites since not many are found through excavations and this is a problem for iron and copper alloy finds as well. One reason for this may be that systematic archaeometallurgical and archaeological dating studies have not been done at existing metal production sites. While this aspect is outside the scope of the present study, what is significant here is to arrive at a better understanding of metal technology and its historical and regional underpinnings by looking at the overall landscape of metal production rather than the individual sites. Given the various limitations, this study extends the initial steps in consolidating the data available from previous field surveys ${ }^{3}$.

While in general remote sensing techniques can be useful in identifying the boundaries of archaeological sites in a finite area, sometimes this technique can also be used to pinpoint the precise location of a site more easily and with less expense ${ }^{18}$. In the United States, the growth of cultural resource management and contract archaeology has been stimulated by the development and use of remote sensing ${ }^{18}$. From the perspective of cultural heritage management, in India there have been various studies which have used remote sensing in archaeology and satellite images to locate historic monuments such as forts and fort walls ${ }^{19-21}$. However, overall, there have been relatively few studies that have integrated archaeology and remote sensing by exploring different methods and adapting them to the Indian archaeological landscape. As pointed out previously ${ }^{19}$, past studies were largely directed by geologists or experts in remote sensing, with occasional inputs by archaeologists. It has also been mentioned that one of the reasons for the limited use of remote sensing in archaeology has been the disconnect between the academics more familiar with conventional methods in archaeology and the remote sensing experts ${ }^{22}$. They also point to the potential for the use of satellite images in archaeological research given that the Indian Space Research Organisation (ISRO) has made great advances with a database of required imagery ${ }^{22}$.

LANDSAT data can be used to classify and map various types of environmental zones by first identifying special categories of land classes on the ground ${ }^{23}$. The present study has used GPS points collected from the field surveys conducted at various sites, as well as satellite images and GIS techniques in order to integrate and analyse the metallurgy sites. However, the study also recognizes the value of the statement that 'given the nonspectacular nature of the majority of archaeological remains, specific remote sensing of archaeological sites using LANDSAT is likely to succeed in only a very few classes $^{23}$. The satellite data used in this study are mostly from LISS IV images, which differ from LANDSAT in that they are of a higher resolution; however, similar problems apply to these images as well. Both controlled samples and non-site locations are required to develop a predictive model $^{23}$. However, there is a cautionary note in that the number of elements has to be sufficient to allow convergence to a solution, and also that the variety of local environment needs to be well represented.

The sites surveyed were located by Jaikishan ${ }^{2}$, who had conducted explorations in this region and identified these sites over the past 10 years. The archaeometallurgical field work of iron and steel production sites in Telangana was carried out in 2010 following reconnaissance-style survey, covering a large area of $30 \mathrm{sq} . \mathrm{km}$ diameter core, extending up to 100 sq. $\mathrm{km}$ (ref. 24). During the field work evidence was recorded from the surface of the archaeometallurgical sites GPS points recorded, ethnography and field notes. The material studied was diagnostic of iron, or iron and steel production and included tap slag, furnace, slag, tuyers, crucibles, remains of the furnace including its walls. A plethora of information with reference to landscape was extracted from the field notes and juxtaposed with Google Earth images and toposheets to contextualize the geographical setting of the archaeometallurgical sites.

A reconnaissance-style field survey was carried out. Archaeologists confront new challenges and integrate new technologies to reconstruct past settlement and physical patterns, and the field survey methods used therefore have to be chosen to suit these challenges ${ }^{25}$. Field survey is a comprehensive study of an area selected for various reasons, including the opportunity it gives to answer questions generated by wider archaeological research ${ }^{26}$. Since the area selected for the survey was rather large to be able to get a broader perspective, the method of survey was adapted to that, and restricted to examining surface materials. The field-walking methods used to cover each of the sites within the surveyed region did not use any 
grids, but the main aim was to understand the landscape and archaeological signatures. The sites recorded were largely, though not exclusively, iron and steel production sites. Both primary iron smelting sites and steel production sites using crucible refining were identified, some being independent and some being inter-connected. By examining the technological debris from individual locations, a composite picture of the technological processes carried out on the particular landscape maybe deduced. The locations of these archaeometallurgical sites were recorded during the field survey as 'date-locations' with the view that post field-work analysis would enumerate better whether these were different archaeological sites or one large site, based on technologies practised and chronology of the sites. This method was followed throughout the field survey and for all the locations visited. Clusters of archaeometallurgical ferrous metal production remains related to primary smelting or secondary refining were recorded. It was also recorded whether the remains were in primary or secondary form, implying those archaeological remains that were found in situ and those that had been moved from their original location respectively. Besides this, the size and depth of the archaeological deposit was approximately measured during the field survey. The present study has drawn some data from these field notes, including description of the landscape as given in the field notes, and further verified on Google Earth and satellite images.

Post field work, the data were processed with the aim of using satellite images to understand the landscape around the sites and current changes in the landscape such as urbanization, which could affect the preservation of the sites. Methods were also explored to identify new sites in areas where the field survey is yet to be carried out (Figure 1). The basic layers, including administrative boundaries and district boundaries relevant to the study area were extracted from Survey of India (SOI) topographic maps. The GPS readings collected in the field were converted into a GIS applicable format, i.e. shape files. Details regarding the sites were converted into GIS

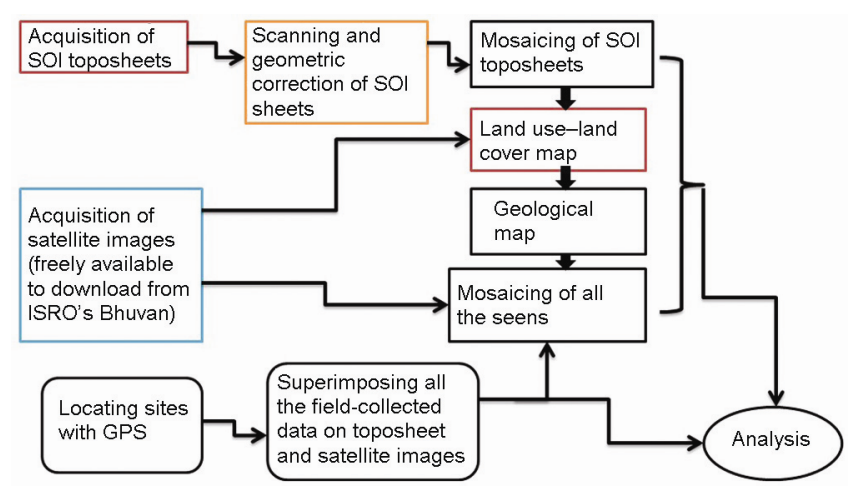

Figure 1. Methodology used in the present study. data bases with information for each site, including period, site group, place names, etc. Geometric rectification was then carried out for the collected SOI map using ERDAS imagine 9.2 software, and all the individual sheets were put together as a mosaic so as to obtain a seamless map. Since the study expected to use satellite images in order to investigate archaeological sites, their location and their surroundings, remotely sensed data such as LISS III (24.5 mt resolution) and LISS IV (5.8 mt resolution) were obtained from NRSC, Hyderabad. To assess the influence of terrain on the distribution of sites, digital elevation models (DEMs) such as SRTM and ASTER were used. The shape files of GPS points from the field survey were then overlaid on satellite images in order to get a sense of the present-day landscape scenario around these sites. The aim of the present study was to look at known iron production sites from Telangana, and identify possible areas where more such sites could be located, i.e. a predictive model for iron production sites. In order to carry this out, only metallurgical sites were chosen from those documented, wherein the archaeological material recovered from these sites could include slag, tuyers, furnace remains, etc. Scenes of these sites were then taken by placing them on the base layer of satellite image within theory district boundaries. These were then analysed to identify whether any patterns could be detected in terms of similar environment or landscape corresponding to the archaeological sites. From the database of the field survey, relevant data pertaining to this study were extracted and attached to the points overlaid on the satellite image. Using the location information, supervised and unsupervised classification was attempted.

The results of the study are provided here in the form of images. The study area was chosen after the field survey location data were plotted on the satellite images which were procured for the area with the densest number of points (Figure 2). Due to the method used during the field survey (reconnaissance style survey), there were geographic areas where no archaeological sites have as yet been located. In order to explore the use of satellite imagery with respect to identifying new sites, hitherto not recorded from ground survey, two methods were used. From the GIS database created as part of the survey, details such as size of site, location, name and GPS points were recovered and a new table of information was created. The satellite images were then analysed, using sitewise information, to understand if there are any details which could be garnered from the satellite image that could be used to further identify sites in areas were no points have as yet been recorded.

A closer look at the satellite images for each site revealed that the sites were located in varying contexts as was also recorded on the field (Figure 3). While some of the sites were near hillocks, others were located within agricultural land, while some were located in towns/ villages. In order to take this one step further, an attempt 
RESEARCH COMMUNICATIONS

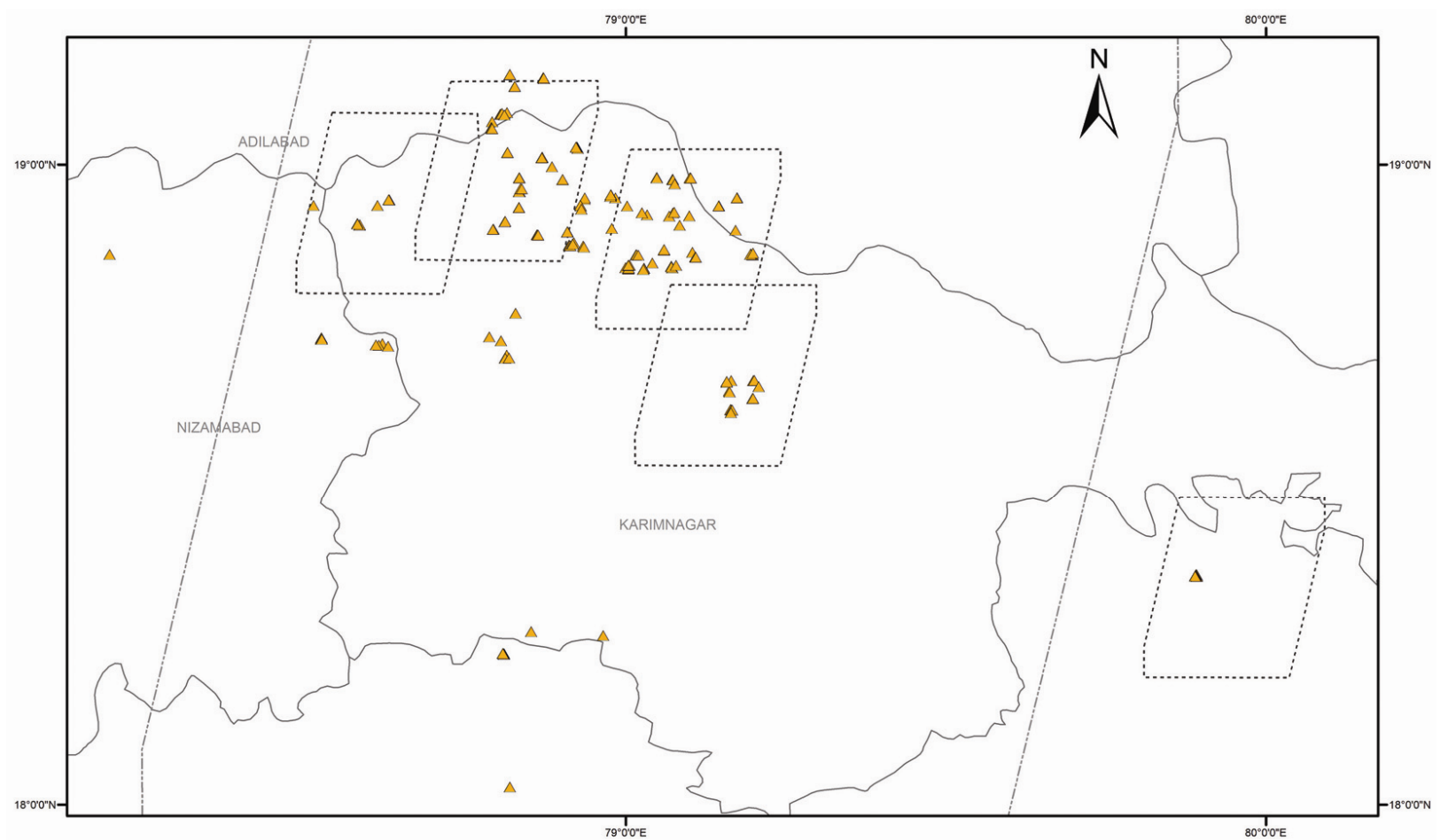

\section{Legend}

$\triangle \quad$ TELANGANA_SITES

\section{District boundaries}

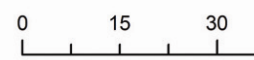

60 kilometres

footprints_IRS-LIS3_telangana_images footprints_IRS-LIS4_telangana_images

Figure 2. Points from field survey plotted on a map showing the study area and available satellite images.
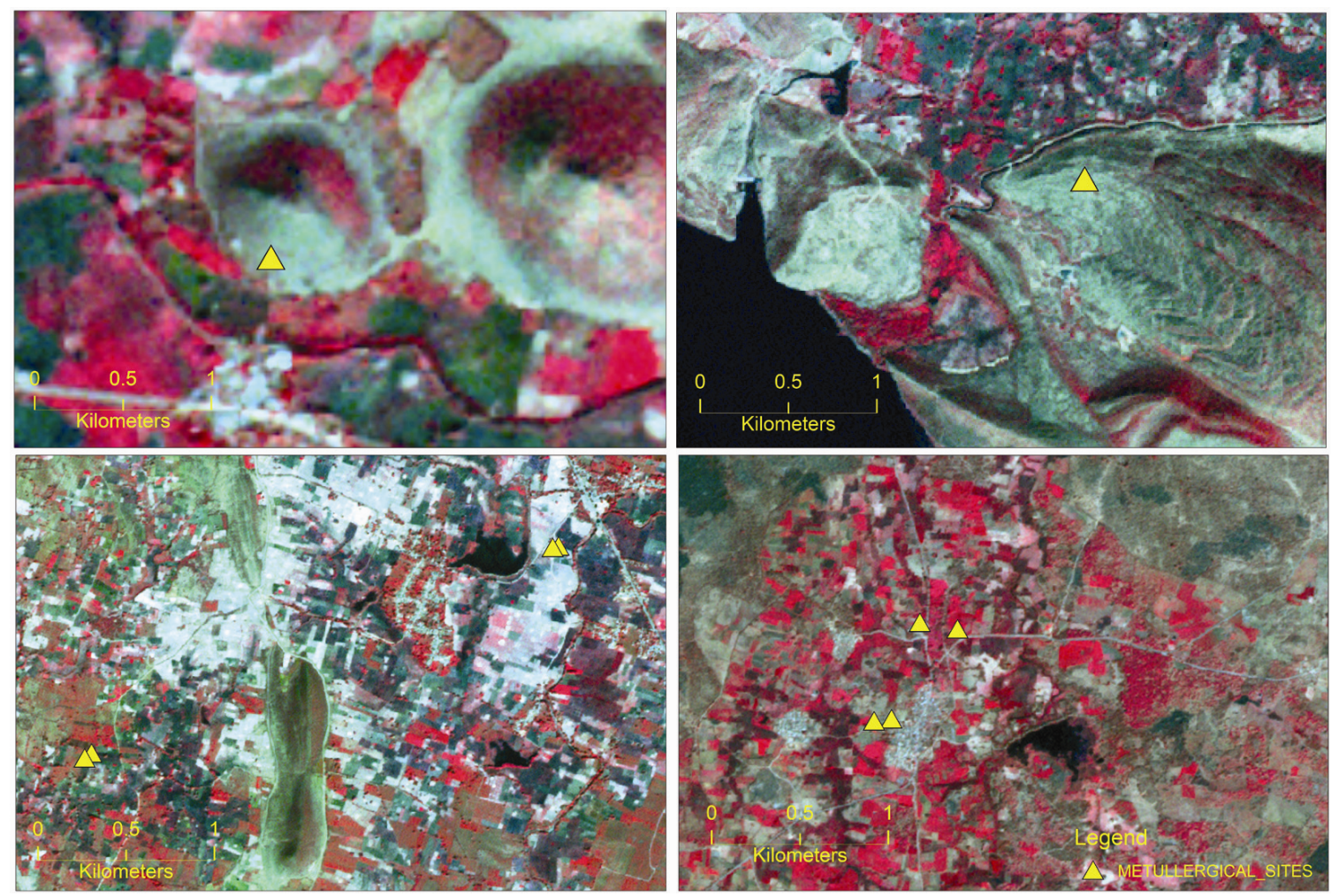

Figure 3. Satellite images with sites. 

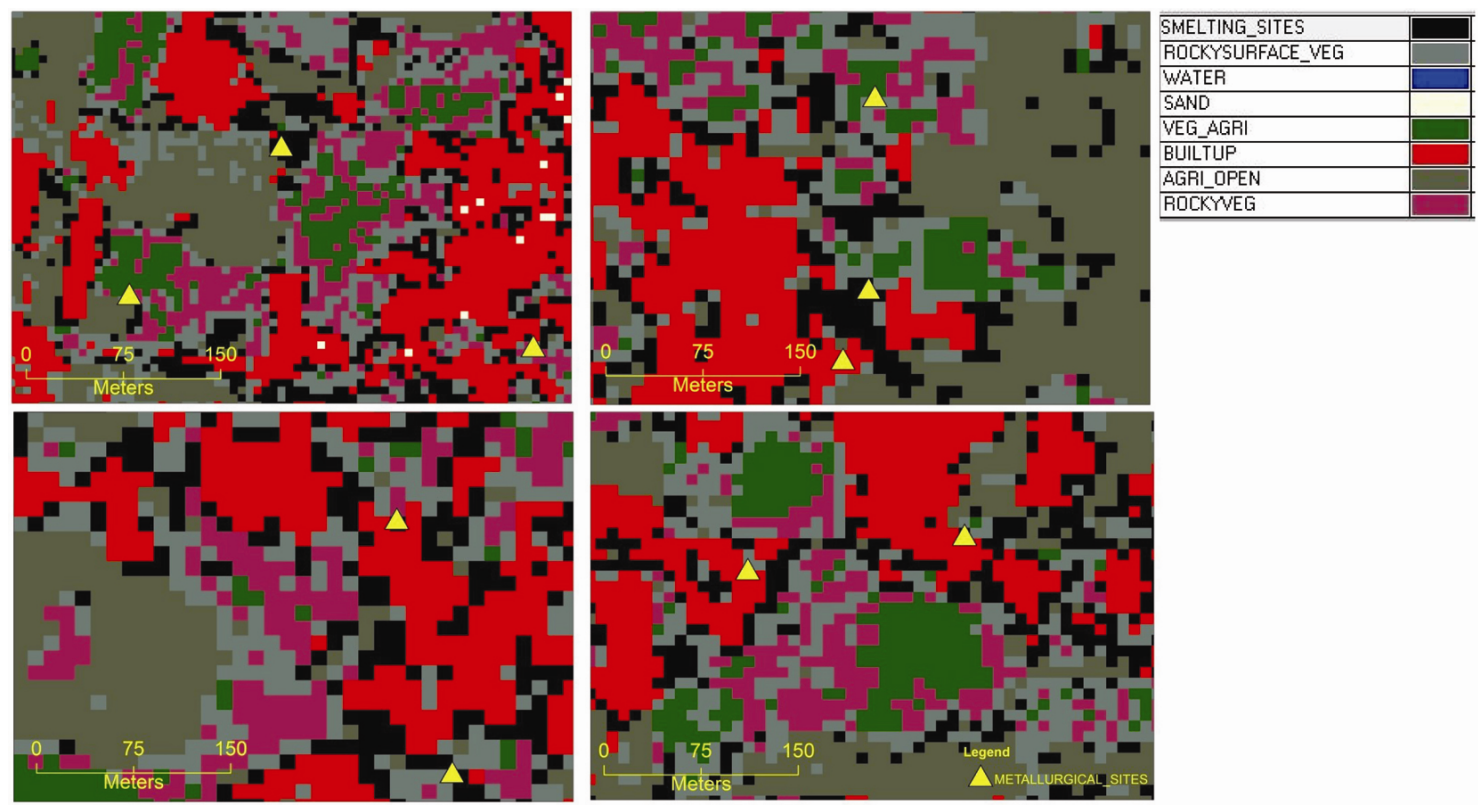

Figure 4. Classification using land-use map.

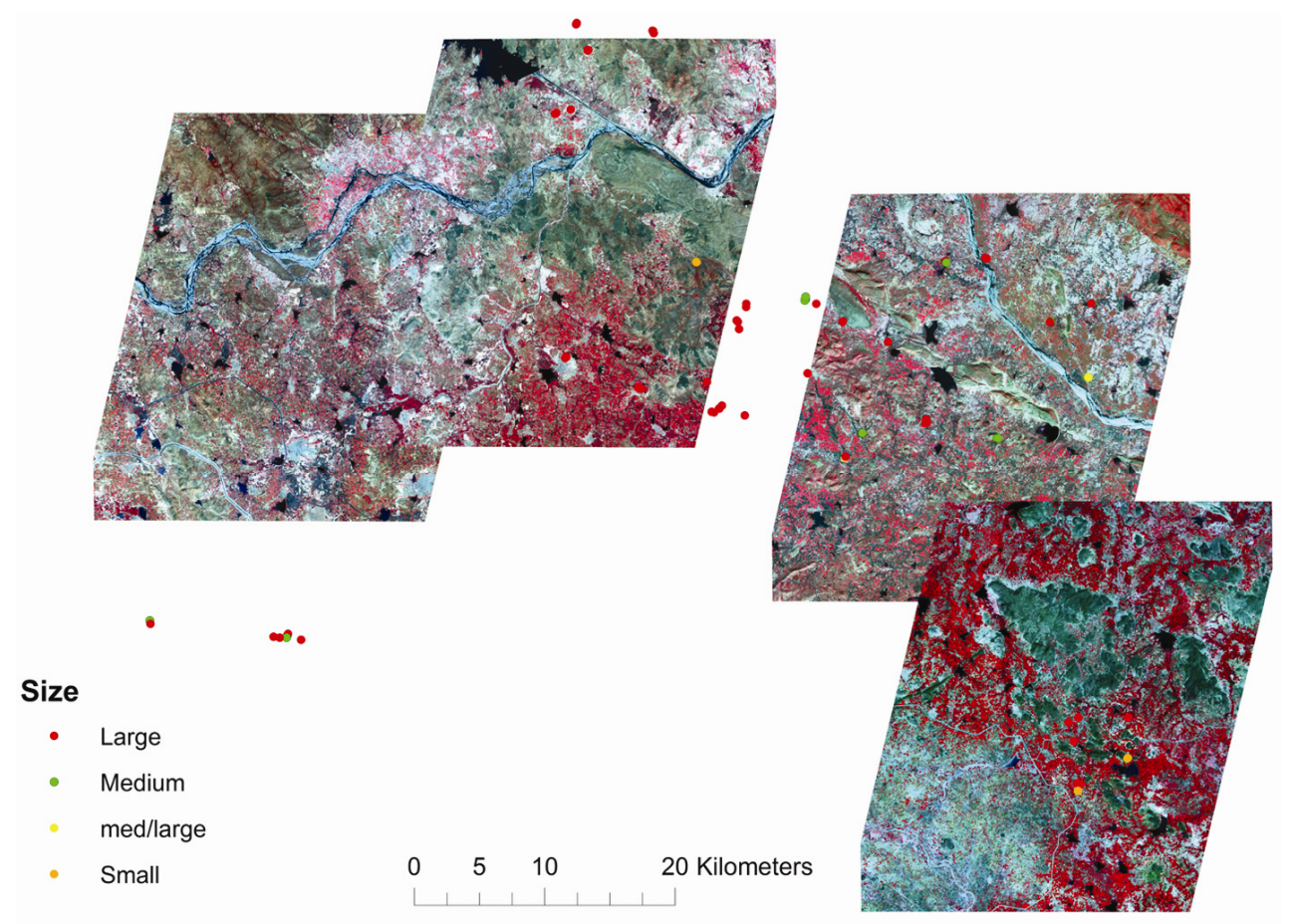

Figure 5. Size and distribution of archaeometallurgical sites from field survey in Telangana, India.

to classify the images with the help of land-use map was made (Figure 4). This, however, revealed that since the sites were located in areas with little commonality, developing a predictive model was difficult.

Of the 245 sites located during the field survey, 183 were metallurgical sites, while the remaining were either geological, prehistoric, historical or single-find spots ${ }^{24,27}$. The field survey carried out some preliminary analysis of technological artefacts and the outcomes show that the study area has a complex history of iron and steel production, and that there is much variation in the technological processes of especially iron smelting within this archaeological dataset ${ }^{27}$. The study has shown that these metallurgical sites are found in varying environmental contexts. The mound/heaps of larger metallurgical sites vary in measurement and the status of preservation. 


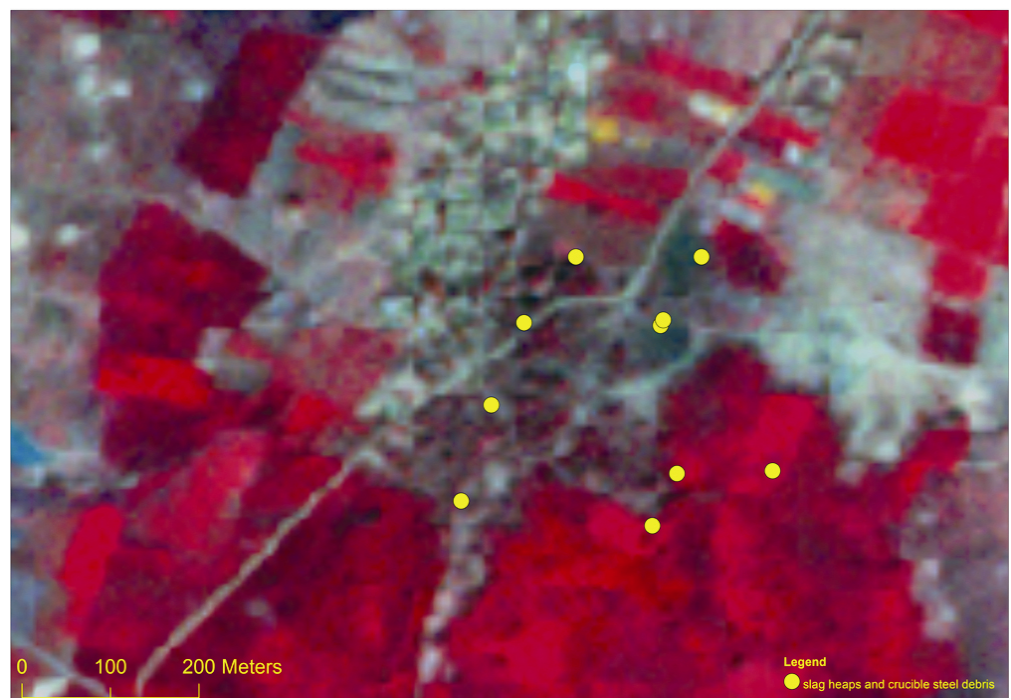

Figure 6. Sites of slag heaps and crucible steel debris at Parasurampalli, Karimnagar district.
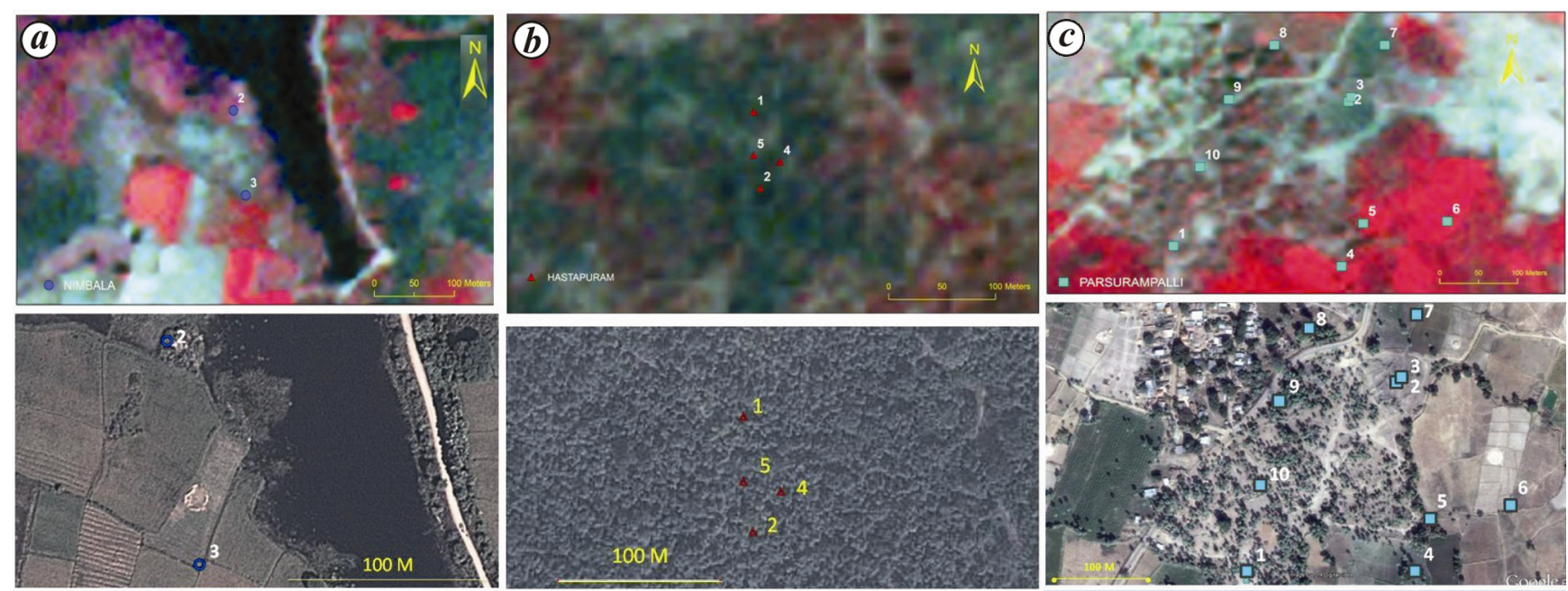

Figure 7. Hastapur (a), Parasurampalli (b) and Nimbala (c) from Karimnagar district located on LISS III and Google Earth images.

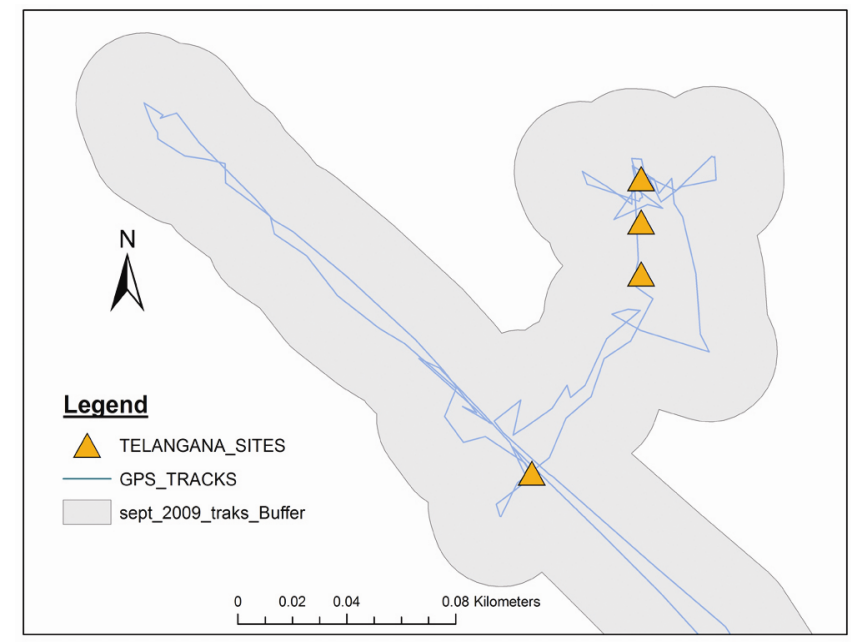

Figure 8. Area covered through reconnaissance style survey.
The field survey team has measured the approximate dimensions of the sites. The sites were divided based on subjective classification during field work and/or during post field work analysis, into (a) small, (b) medium and (c) large (Figure 5). During the course of the present study, only information from large sites was extracted in order to understand the dimensions of the archaeological remains in the field. However, 4 of the 14 sites for which the extent of slag or crucible waste heap remains were measured, recorded less than $1 \mathrm{~m}$ in height, out of the 27 smelting or crucible sites which fall within the category of large sites. The sites were, however, much harder to locate visually on the satellite images. The study also examined two sites which had the largest slag heap remains according to field notes for a more, in-depth, site-wise study. The first one was the site of Pedda Belalla from Adilabad district. This site is located amidst cultivation 
fields. However, seven different 'date-locations' of archaeological remains were located from this area. All seven according to the field survey notes were primary and deep deposits, though some of them were disturbed due to cultivation. The archaeological remains identified at the site included tap slag, furnace slag, remains of furnace walls and tuyeres. The measurements of two slag heaps recorded at two 'date-locations' measured approximately $45 \times 25 \mathrm{~m}$, oriented $\mathrm{N}-\mathrm{S}, 1.5 \mathrm{~m}$ high, forming a long, low mound and approximately $40 \times 20 \mathrm{~m}$ and $1.5 \mathrm{~m}$ high respectively. The second site was noticed to have been partially cleared to develop cultivation fields. (The remaining five archaeometallurgical sites were destroyed during the laying of a road.) This site was located on Google Earth and satellite images. However, both were not visible on the satellite image, though the description of the site from field notes, including the cultivated field matched that visually seen on both.

Similarly, at Parasurampalli, Warangal district, a site located on the outskirts of a village and within agricultural fields and open scrub land, the size of slag heaps varied from $60 \times 50 \mathrm{~m}$ in width and breadth, to $40 \times$ $45 \times 2 \mathrm{~m}$ is width, breadth and height (Figures 6 and 7). The second recorded slag heap mound was noticed to have been disturbed by road works, and may have originally been part of a larger mound. The same site also had remains of crucibles, and crucible waste heaps ranged in size from $25 \times 10 \times 1.5 \mathrm{~m}$ to $30 \times 45 \times 2 \mathrm{~m}$ in width, breadth and height. Both these sites were noticed to have been on the periphery of the nearby village, in open scrubland. While some damage from bull-dozers had exposed sections within the mound, they remained relatively undisturbed. The archaeometallurgical remains at this site include crucibles, smelting slag, tuyers and furnace wall remains. A total of 11 'date-locations' were documented at this site. Despite the fact that the sites were recorded to have larger size, when the Google Earth image was matched with the satellite image, they could not be discerned on the satellite image.

Reconnaissance style survey (Figure 8) is a method of field survey (which is not a grid-based survey) where a team would thoroughly scan a given dimension of area. This is more conducive for carrying out field surveys, especially where previous studies are few. However, since we used GPS, all our tracks have been recorded and can be used for future reference. Archaeological structures that have surviving features such as fortifications or canals or streets layout, etc. can indeed be picked-up through synoptic view. However, in the present study we were looking for remnants of industrial process (largescale iron smelting furnaces), which do not seem to have had much of an association with built structures. Given that archaeometallurgical slag heaps represent mainly refractory and furnace materials as debris from pyrometallurgical processes, these cannot be distinguished easily from the other soil, vegetation and landscape features. But in order to understand these aspects, it may be required to undertake a thorough (inch by inch) survey of a carefully selected sample area. The sample area should have typical characteristics of the local natural resources. Once this is done, satellite images can be revisited and analysed again. After the collected material has been analysed with a better understanding of it, the locations based on the material can be analysed afresh using GIS together with satellite images. This study concludes that it is not possible to distinguish archaeometallurgical ferrous metal production sites in the northern Telangana region from satellite imagery based on the criterion of size alone, even those sites of substantial dimension of 25-60 m without integrating it further with other parameters of landscape from the field survey information.

1. Lowe, T. L., Refractories in high carbon iron processing: a preliminary study of Deccani wootz making crucibles. In Ceramics and Civilization (ed. Kinger, W. D.), The American Ceramic Society, Pittsburgh, 1990, pp. 237-250.

2. Jaikishan, S., Iron and wootz steel industry in northern Telangana. Telangana Jagruthi, Hyderabad, 2009.

3. Juleff, G., Srinivasan, S. and Ranganathan, S., Pioneering Metallurgy: Telangana Field Survey Interim Report 2011, National Institute of Advanced Studies (NIAS), Bengaluru, 2011.

4. Bronson, B., The making and selling of wootz-a crucible steel of India. Archaeomaterials, 1986, 1, 13-51.

5. Srinivasan, S., On higher carbon and crucible steels in southern India: further insights from Mel-siruvalur, megalithic Kodumanal and early historic Pattinam. Indian J. Hist. Sci.., 2007, 42(4), 673695.

6. Srinivasan, S. and Ranganathan, S., India's Legendary Wootz Steel: An Advanced Material of the Ancient World, NIAS, Bengaluru, 2004.

7. Srinivasan, S., Indian iron and steel, with special reference to southern India. In World of Iron (eds Humphris, J. and Rehren, T. H.), London, Archetype Press, 2013, pp. 83-90.

8. Singh, S. D., Iron in ancient India. J. Econ. Soc. Hist. Orient, 1962, 212-216.

9. Ray, A. and Chakrabarti, D. K., Studies in Ancient Indian technology and production. J. Econ. Soc. Hist. Orient, 1975, 18(2), 219-232.

10. Agarwal, D. P. and Kharakwal, J. S., Bronze and Iron Ages in South Asia, Aryan Books International, New Delhi, 2003.

11. Tripathi, V., The Age of Iron in South Asia: Legacy and Tradition, Aryan Books International, New Delhi, 2001.

12. Chakrabarti, D. K., The beginning of Iron in India. In A Source Book of Indian Archaeology Vol 2 (eds Allchin, F. R. and Chakrabarti, D. K.), Minishram Manoharlal, New Delhi, 1997, pp. 378391.

13. Krishna Sastry, V. V., Megalithic cultures: the iron age. In Pre and Protohistoric Andhra Pradesh up to 500 BC (ed Murty, M. L. K.), Orient Longman, New Delhi, 2003, p. 107.

14. Subrahmanyam, B. R., Iron age in Andhra Pradesh, archaeology of Andhra Pradesh. In Archaeology of Andhra Pradesh (ed. Krishna Sastry, V. V.), Government of Andhra Pradesh, Hyderabad, 1987.

15. Biswas, A. K., Minerals and Metals in Premodern India, D. K. Printworld, New Delhi, 2002.

16. Srinivasan, S., Sinopoli, C., Morrison, K., Gopal, R. and Ranganathan, S., South Indian Iron Age iron and high carbon steel: with reference to Kadebakele and comparative insights from Melsiruvalur, Metallurgy and Civilisation: Eurasia and Beyond. In 
Proceedings of the 6th International Conference on the Beginning of the use of Metals and Alloys (BUMA VI), Archetype Books, London, 2009, pp. 116-122.

17. Sasisekaran, B., Metallurgy and metal industry in ancient Tamilnadu - an archaeological study. Indian J. Hist. Sci., 2002, 37(1), 17-29.

18. Parrington, M., Remote sensing. Annu. Rev. Anthropol., 1983, 12, 105-124.

19. Pappu, S., Kumar, A., Ravindranath, S. and Raju, U., Applications of satellite remote sensing for research and heritage management in Indian prehistory. J. Archaeol. Sci., 2010, 37, 2316-2331.

20. Rajani, M. B., Patra, S. K. and Mamta, V., Space observation for generating 3D perspective views and its implication to the study of the archaeological site of Badami in India. J. Cult. Heritage, 2009, 10(1), 20-26.

21. Singh, V. and Singh, U. C., Mapping archaeological monuments. Indian J. Sci. Technol., 2014, 1, 27-28.

22. Rajani, M. B. and Kasturirangan, K., Satellite image and India's past. In Proceedings of a Workshop organized under the aegis of International Centre for Theoretical Sciences, Mangalore, 2011.

23. Custer, J. F., Eveleigh, T., Klemas, V. and Wells, I., Application of LANDSAT data and synoptic remote sensing to predictive models for prehistoric archaeological sites: an example from the Delaware coastal plain. Am. Antiq., 1986, 51, 572-588.

24. Oltean, I. A., Rajani, M. B. and Nalini, N. S., Archaeometallurgy in the Telangana region: a GIS approach in pioneering metallurgy: the origins of iron and steel making in the southern Indian subcontinent. In Pioneering Metallurgy: Telangana Field Survey Interim Report (eds Juleff, G., Srinivasan, S. and Ranganathan, S.), NIAS, Bengaluru, 2011, pp. 20-21.

25. Kantner, J., The archaeology of regions: from discrete analytical toolkit to ubiquitous spatial perspective. J. Archaeol. Res., 2008, 16(1), 37-81.

26. Greene, K. and Moore, T., Archaeology: An Introduction, Routledge, London, 2002, 5 th edn.

27. Juleff, G. and Gilmour, B., Telangana field survey: aims, methods and outcomes. In Pioneering Metallurgy: Telangana Field Survey Interim Report (eds Juleff, G., Srinivasan, S. and Ranganathan, S.), NIAS, Bengaluru, 2011, pp. 7-11.

ACKNOWLEDGEMENTS. We thank ISRO's RESPOND programme which funded this project and Dr A. S. Rajawat (Space Applications Centre, Ahmedabad), for inputs. We also thank N. S. Nalini for assistance in the field and post field work analysis. Dr Gill Juleff, Dr Jaikishan and the rest of the UKIERI 'Pioneering metallurgy' project for making available the data collected from the field survey. S.H. was affiliated to NIAS, Bengaluru for a major part of the completion of this work and would like to thank the institute for logistic support during this project.

Received 7 December 2015; accepted 12 July 2016

doi: $10.18520 / \mathrm{cs} / \mathrm{v} 111 / \mathrm{i} 9 / 1536-1543$

\section{Presumptive case of ciguatera fish poisoning in Mangalore, India}

\author{
Moger Rajeish, Malathi Shekar, \\ Hoovinahalli Nataraju Madhushree and \\ Moleyur Nagarajappa Venugopal*
}

Department of Fisheries Microbiology, Karnataka Veterinary, Animal and Fisheries Sciences, University, College of Fisheries, Mangalore 575 002, India

Ciguatera fish poisoning (CFP) occurs when humans ingest fishes contaminated with ciguatoxins (CTXs). Two individuals developed suspected ciguatera poisoning after consuming unknown fish purchased from a local market in Mangalore, India. DNA barcoding confirmed the fish under study to be Lutjanus bohar. A mouse bioassay study detected high levels of CTX in the implicated fish. Mice injected with toxin showed typical symptoms of CTX poisoning. To the best of our knowledge, this is a first case report of CFP due to consumption of $L$. bohar in India.

Keywords: Ciguatera fish poisoning, cytochrome oxidase, DNA barcoding, Lutjanus bohar, mouse bioassay.

Ciguatera FISH POISONING (CFP) is the human intoxication caused by consumption of fish which have accumulated ciguatoxins (CTXs). Ciguatoxin is a colourless, odourless, heat stable, lipid-soluble polyether which is not destroyed by the cooking process ${ }^{1}$. Ciguatoxin is primarily produced by dinoflagellates of the genus Gambierdiscus. Herbivorous fish that graze on these dinoflagellates bio-accumulate the toxin, which then gets passed on to predatory fish via the marine food chain and finally to humans ${ }^{2}$. Distribution of ciguateric fish is restricted to tropical and subtropical waters, being particularly common in Pacific and Indian oceanic regions and in the tropical Caribbean $\mathrm{Sea}^{3}$. Depending on their geographical origin and chemical structure, CTXs are classified as Pacific (P-CTX), the Indian Ocean (I-CTX) and the Caribbean (C-CTX) of which P-CTXs are considered to be the most potent ${ }^{4,5}$. CFP outbreaks outside of endemic areas have been attributed to consumption of imported toxic fish ${ }^{6}$ and expanding biogeographical range of Gamberdiscus spp. and ciguatoxic fish ${ }^{7,8}$.

CFP symptoms vary with the regional origin of the toxin ${ }^{9}$ and occur within $0.5-12 \mathrm{~h}$ of toxic fish consumption ${ }^{10}$. Clinical presentation of CFP is characterized by a range of gastrointestinal symptoms that include abdominal pain, nausea, vomiting and diarrhoea, usually followed by neurological symptoms such as pruritus (itchy skin), dysesthaesia (reversal of hot and cold sensations), numbness and tingling in the extremities, paresthesia, ataxia, and

*For correspondence. (e-mail: mnvenu@rediffmail.com) 